\title{
Optimal power dispatch of a grid tied-battery-photovoltaic system supplying heat pump water heaters
}

\author{
Sam M. Sichilalu*, Xiaohua Xia \\ Centre of New Energy Systems, Department of Electrical, Electronic and Computer Engineering, University of \\ Pretoria, Pretoria 0002, South Africa
}

\begin{abstract}
The aim of this paper is to develop an optimal scheduling strategy model for a grid-tied photovoltaic (PV) system to power a heat pump water heater (HPWH). The system is composed of PV modules that are grid-tied and a backup battery. The PV is capable of supplying power simultaneously to the HPWH and domestic load, whilst the grid and the battery are complementary sources. The objective function of this model is energy cost. The time-of-use (TOU) electricity tariff is taken into account in the optimal scheduling model. The control variables are the power flows within the branches of the system. The optimal control strategy of this grid-tied PV system can be implemented to reduce the energy cost while meeting the technical and operational constraints. This model has shown to have more economic benefits than solar thermal heaters, because of the possibility to turn the dwelling into net-zero energy or energy-positive buildings with the attractiveness of the feed-in tariff. A case study is done based on 3x16 kW HPWH installed at a Pretoria hotel in South Africa. Simulations are run for a year on selected seasonal date using the actual HPWH demand. The optimal control results show how the battery status of charge and TOU affect the power scheduling strategy of the HPWH. The energy and cost savings are presented in this paper as well.
\end{abstract}

Keywords: Heat pump water heater; Optimal scheduling; Photovoltaic; Net-zero energy buildings; Time-of-use tariff

\footnotetext{
${ }^{*}$ Corresponding author. Tel. +27 12420 6767; Fax +27 123625000.

Email address: Sam.Sichilalu@up.ac.za ; sichgroup@yahoo.com (Sam M. Sichilalu )
} 


\begin{tabular}{|c|c|}
\hline \multicolumn{2}{|l|}{ Nomenclature } \\
\hline$P_{i}$ & control variable, which is the power in the $i$-th branch $(k W)$ \\
\hline "min" and "max" & minimum and maximum of the variable \\
\hline$R$ & South African Rands (ZAR) \\
\hline$p$ & TOU electricity price $(R / k W h)$ \\
\hline$N$ & total number of sampling intervals \\
\hline$t_{s}$ and $k$ & sampling time (hour) and $k^{\text {th }}$ sampling interval \\
\hline$\omega$ & weighting factor \\
\hline$p_{c}$ & photovoltaic feed-in tariff $(R / k W h)$ \\
\hline$P_{h p}$ & heat pump water heater power demand $(\mathrm{kW})$ \\
\hline $\mathrm{COP}$ & coefficient of performance \\
\hline$P_{d l}$ & domestic appliances power demand $(k W)$ \\
\hline$P_{p v}$ & photovoltaic power output $(k W)$ \\
\hline$B_{c}(t)$ & battery capacity at every given time $t$ in $(k W h)$ \\
\hline$\eta_{c}$ & battery charging efficiency \\
\hline$\eta_{d}$ & battery discharging efficiency \\
\hline$B_{c}(0)$ & initial status of charge of the battery \\
\hline SOE & battery status of energy $(k W h)$ \\
\hline$B_{c}^{\max }$ & maximum battery rated capacity in $(A-h)$ \\
\hline$\eta_{i}$ & inverter efficiency \\
\hline NERSA & National Energy Regulator of South Africa \\
\hline REFIT & Renewable Energy Feed-in Tariff for South Africa \\
\hline REPA & Renewable Energy Purchasing Agency \\
\hline MINLP & Mixed Integer Nonlinear Program \\
\hline
\end{tabular}

\section{Introduction}

Heat pump water heaters (HPWH) have gained wide usage [1] in offering economical means of heat recovery from the environment for industrial and domestic applications. The most predominant usage [2], [3] of the HPWH is for water and space heating. Heat pumps have low energy consumption, approximately two thirds [4] less than resistive element water heaters owing to its coefficient of performance (COP). Hawlader [5] developed a detailed mathematical model for most of the parameters of the heat pump system. Research work to improve the technical and opera- 
tional efficiency of HPWH has been extensively presented in [6], [7], [8], [9] and [10]. While Yin [11] presented a novel design of photovoltaic (PV)/thermal energy for an energy-efficiency building, various authors [12], [13], [14] and [15] looked into different PV/thermal energy design configurations and optimization of the COP of the HPWH to achieve the required thermal comfort, both for water and space heating. However technological challenges, as mentioned by Chua [1] on initial costs, system designing and integration of the heat pumps still exit. In this research paper, the heat pump is used in demand side management (DSM) as an efficient means of providing the thermal energy requirements of the building.

The integration of distributed renewable energy sources (DRE) into buildings provides huge potential in overall energy saving and management. These DRE can either be on/off site powering the entire building (zero energy buildings) or grid connected which are referred to as net-zero energy buildings (NZEBs). The energy consumed in buildings [16], [17] accounts for 40\% of global energy production. Therefore, most countries are encouraging and implementing regulatory measures at national level [18] to achieve NZEBs. Most researchers [19], [20], [21] have provided various methodologies and approaches for calculation of NZEBs. These formulations and methodologies, however, lead to different interpretation of energy savings in the building. Marszal [18] pointed out that a practical integration of DRE with the grid to achieve the NZEBs is still a big challenge.

The hybrid photovoltaic (PV) system in [22] presented a model for load shifting and maximum demand control using the HPWH as the major correction equipment. Several renewable hybrid system designs to power small loads in urban and rural communities are presented in [23], [24], [25], [26] and [27] where the authors outlined the need for optimal designing, sizing and control. The optimization and maximum power tracking of solar PV are intensively explained in [28],[29] and [30]. The optimal energy scheduling for a practical application in NZEBs still seems infeasible owing to constraints on technology, integration and operations, as mentioned in [18]. Most of the work in finding solutions for NZEBs at building design stage, carbon emissions and energy balance was done by [31] and [32].

Despite all the above success in optimal designs and control, little research has been done on a grid-tied PV system to power HPWH and they remain uneconomical [4] in most developing countries (e.g., South Africa), with only 16\% market penetration. Nevertheless, nowadays heat pumps are slowly becoming attractive for usage in hot water generation and DSM because of success in design and system integration, which is lowering the initial costs. There is still low 
application of renewable energy such as biomass, wind and solar to power energy-efficient loads such as HPWHs. The proper integration of these sources and using HPWH could reduce the power utility's maximum demand and improve the security of the supply. Most countries at policy level are beginning to introduce attractive feed-in and rebate systems for using greener energy and energy-efficient load like heat pumps. These policies encourage building owner to turn their dwelling into zero/positive energy buildings. Some work has been done in this regard, Ikegami [33] attempted to develop an optimal control (OC) model on an ideal HPWH for using it as a DSM correction tool.

However, this paper reports on a first attempt to design a greener, practical and economically attractive optimal control model for a grid-tied PV system that considers the time-of-use (TOU) electricity tariff to supply the HPWH. In this model the battery is not charged by the PV as per usual case, instead it is being used as a storage of cheaper-to-purchase (off-peak) grid energy and make it available during peak demand. The model present an optimal control breakthrough in the integration of renewable resources to power the HPWH and the possibility of turning dwelling into energy/cost-positive building. The other contribution is the application of Mixed Integer NonLinear Programming (MINLP) to this complex nonlinear engineering problem. The scheduling strategy of our model can be adopted by building owners intending to achieve net-zero or positiveenergy buildings. It provides a practical model for energy savings through integration of DRE to the grid, with the battery being charged by the grid during off-peak in order to minimise cost. The OC used the cheaper stored energy and the PV to power the HPWH whenever sufficient, the excess PV power was sold to the grid. The feed-in of PV energy to the grid could as well qualify the building owner to the prevailing rebate and incentives on renewable energy trade-off.

This paper is structured as follows: Section 2 is the mathematical formulation, Section 3 is the simulation results and discussion. The last Section 4 , is the conclusion.

\section{Mathematical formulation}

\subsection{Schematic model layout}

The optimal control (OC) strategy schematic layout in Figure 1 consist of 5 sub-models: the power utility grid 230/400V, PV modules with grid-interactive inverter, battery with inverter/charger, heat pump water heater (HPWH) and the domestic load. The grid can supply power $P_{1}(t)$ directly through a switch $u_{1}(t)$ the HPWH, while $P_{2}(t)$ is for charging the battery and $P_{5}(t)$ supplies the 
domestic load. The battery is used to store off-peak cheaper energy from the grid through $P_{2}(t)$, this off-peak stored energy is made available during peak demand to supplement the loads. The battery supplies $P_{3}(t), P_{4}(t)$ to the HPWH and domestic load respectively. The PV modules can supply power to all the loads and at the same time feed-in to the grid, $P_{7}(t)$ supplies the HPWH, $P_{6}(t)$ supplies the domestic load and $P_{8}(t)$ is the excess power from the PV which is sold to the grid. The proposed model is controlled by an energy management systems, which are not shown in the schematic layout. The power flows $P_{1}(t), P_{2}(t), P_{3}(t), P_{4}(t), P_{5}(t), P_{6}(t), P_{7}(t), P_{8}(t)$ and the switch $u_{1}(t)$ in Figure 1 are the control variables in this model.

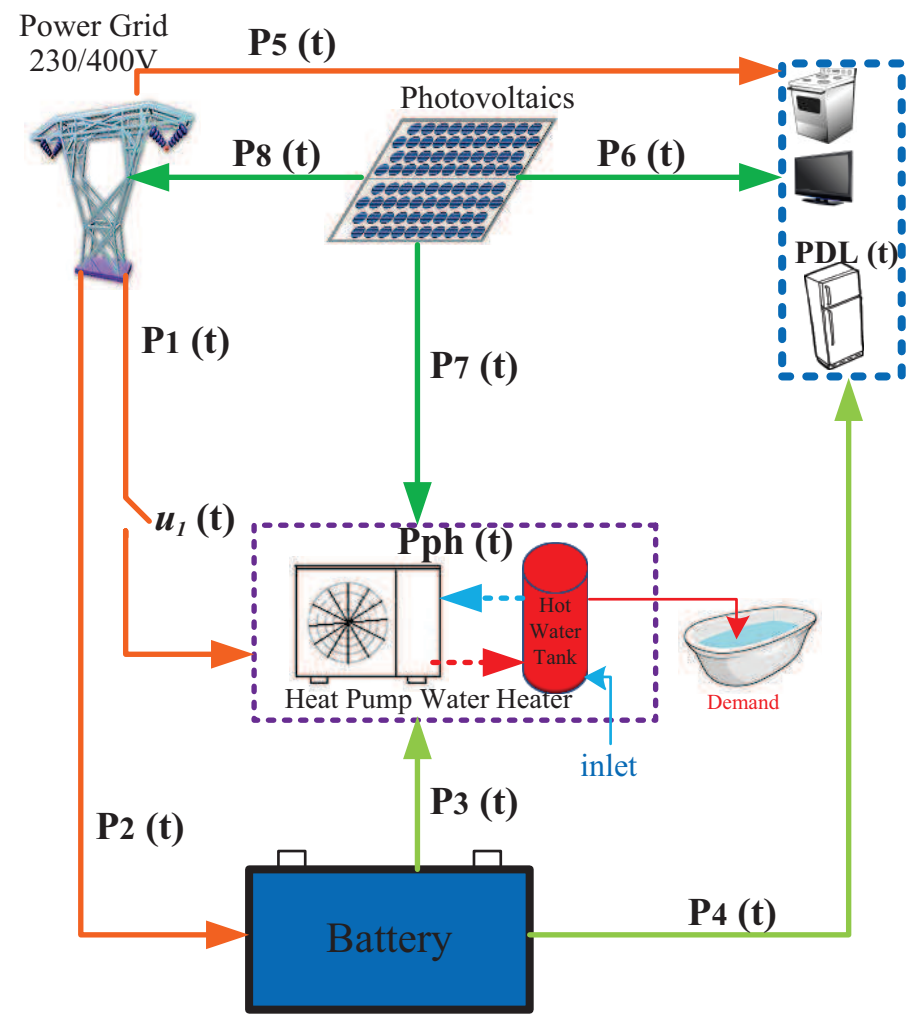

Figure 1: Schematic layout of the model.

Here the grid act as the excess PV power storage system, unlike using the PV power to charge the battery. The selling of PV power to the grid attracts rebates and other incentives in most countries in addition to the revenue generation. The battery is charged during the cheapest TOU tariff and make usage of this cheaper-to-buy stored energy during the peak demand. The weighting factor was incorporated in the objective function as factor for selling of excess PV power to the grid, based on the desired effects of each client. The formulation of optimal control of the HPWH 
was achieved using the operation constraints and objective function.

\subsection{Sub-models}

\section{Heat pump}

The heat pump is modeled as a fixed load at a discrete time interval with respect to the power demand. The power demand of the heat pump is taken to be proportional to the thermal load requirements and inversely proportion to its COP. Though in [5] mathematical model of heat pump is presented, however, in this study the HPWH is modeled as a fixed load and regarded as an input data based on annual demand profile taken from a case study in South Africa. The grid can supply $P_{1}(k)$ to the HPWH direct through a switch $u_{1}(k)$, this supply route has a continuous and binary variable which is a nonlinear constraint. The HPWH is mainly supplied by the solar PV $P_{7}(k)$ and battery $P_{3}(k)$ whenever available. In this paper, for simplicity we denoted $P_{i}(k) t_{s}=P_{i}(k)$, with $i=1, \ldots, 9$ being the number of the control variables. The sampling time $t_{s}$ is one hour and the sampling interval $k=1, \ldots, N$, where $N=24$. The HPWH energy balance is given as:

$$
\begin{gathered}
P_{1}(k) u_{1}(k)+P_{3}(k)+P_{7}(k)=P_{h p}(k), \\
P_{h p}^{\min } \leq P_{h p}(k) \leq P_{h p}^{\max },
\end{gathered}
$$

\section{Photovoltaic}

The PV is treated as input data which is a variable power source, varying from zero to maximum rated power as shown in equation (4). The PV power acts as the main power source for the HPWH whenever available. The battery is a supplementary source. However, during the period when the HPWH demand is too high for the PV and the battery to meet, the grid supply $\left(P_{1}\right)$ is switched on through switch $u_{1}(k)$. The generated PV power is connected to the grid interactive inverter to enable selling. The inverter efficiency $\eta_{i}$ is taken from the case study. The energy balance of the PV output is shown in equation (3).

$$
\begin{gathered}
0 \leq P_{6}(k)+P_{7}(k)+P_{8}(k) \leq \eta_{i} P_{p v}(k), \\
0 \leq P_{p v}(k) \leq P_{p v}^{\max }
\end{gathered}
$$


The battery is charged with $P_{2}(k)$ from the grid. The stored energy in the battery is made available during peak demand and whenever its uneconomical to use the PV or the grid power. The battery performance index is its status of energy (SOE), which depend on the initial state of charge $B_{c}(t-1)$ and the power discharging to the loads. The SOE of the battery at any given time $t$ and the flow of power from $t-1$ to $t$ is governed the battery dynamic given in equation (5), where $t=1, \ldots, 24$.

$$
B_{c}(t)=B_{c}(t-1)+\eta_{i} \eta_{c} P_{2}(t)-\eta_{i} \eta_{d} P_{3}(t)-\eta_{i} \eta_{d} P_{4}(t)
$$

where $\eta_{c}=0.91$ and $\eta_{d}=0.85$ are the battery charging and discharging efficiency respectively. $\eta_{i}=0.92$ is the round trip grid-tied inverter efficiency converting alternating current (AC) to direct current (DC) to charge the battery and vice-versa to the loads. $\eta_{c} P_{2}(t)$ is the charging power accepted by the battery from the grid whereas $\eta_{d} P_{3}(t), \eta_{d} P_{4}(t)$ are the discharged power to the HPWH and domestic load respectively. Here $B_{c}(t)$ is battery SOE in $(k W h)$ and $\tau=1, \ldots, k$, therefore, from equation (5) the generalised discrete battery dynamics is expressed as:

$$
B_{c}(k)=B_{c}(0)+\eta_{i} \eta_{c} \sum_{\tau=1}^{k} P_{2}(\tau)-\eta_{i} \eta_{d} \sum_{\tau=1}^{k} P_{3}(\tau)-\eta_{i} \eta_{d} \sum_{\tau=1}^{k} P_{4}(\tau),
$$

However, utilization of the power from the battery must be within its nominal range $B_{c}^{\min }$ and $B_{c}^{\max }$ in order to maximise the battery life cycle.

$$
B_{c}^{\min } \leq B_{c}(k) \leq B_{c}^{\max },
$$

where $B_{c}^{\min }$ and $B_{c}^{\max }$ are the minimum and maximum nominal capacity respectively. In this model, a step down transformer is avoided since the voltages is at domestic level, rather the grid-interactive inverter/charger with an efficiency of $92 \%$ is used.

\section{Power grid}

The grid is modeled as an infinite busbar at domestic voltage levels of 230/400V capable of simultaneously supplying and accepting power from the DREs connected through the gridinteractive inverters without transformers. The TOU electricity tariff is factored in the model, which is one of the most important optimal control parameter. In South Africa, Eskom is the main power supply utility company which has dynamic pricing system $p(t)$ or rather 
TOU tariff, off-peak $\left(p_{o}\right)$, standard $\left(p_{s}\right)$ and peak $\left(p_{p}\right)$. In this study, the recent Eskom ${ }^{1}$ Megaflex Active Energy-TOU tariff was used. The DREs feed-in tariff is regulated by the National Energy Regulator of South Africa (NERSA) ${ }^{2}$, which commissioned a Renewable Energy Feed-in Tariff (REFIT) for South Africa. NERSA through the Renewable Energy Purchasing Agency (REPA) which in South African case, is the Single Buyer Office (SBO) of the national electricity utility Eskom under phase II (Photovoltaic systems large ground or roof mounted) pegged $\mathrm{REFIT}^{3}$ at $3.94 \mathrm{R} / \mathrm{kWh}$. In this model $p_{c}$ was used to denote the PV feed-in tariff. These regulatory measures and SBO provide the necessary incentive to the DRE developers and private investors. They guarantee the availability of renewable energy market and provide venture capitalist a low financial risk. The Eskom TOU electricity tariff is:

$$
p(t)= \begin{cases}p_{o}=0.3656 \mathrm{R} / \mathrm{kWh} \quad \text { if } t \in[0,7] \cup[23,24], \\ p_{s}=0.6733 \mathrm{R} / \mathrm{kWh} \quad \text { if } t \in[7,8] \cup[11,19] \cup[21,23], \\ p_{p}=2.2225 \mathrm{R} / \mathrm{kWh} \quad \text { if } t \in[8,11] \cup[19,21],\end{cases}
$$

where $R$ is the South African Rand and time $t$ is the whole period of the day with $t=$ $0, \ldots, 23$.

\section{Domestic loads}

The domestic appliances $P_{d l}$ are modeled as the total power demand of all other loads in the building except the HPWH and constitute the input data for that period.

$$
P_{4}(k)+P_{5}(k)+P_{6}(k)=P_{d l}(k),
$$

\subsection{Objective function}

The objective function is expressed in a discrete-time domain at sampling time $t_{s}$, to minimize grid energy costs $J$ while maximizing the solar energy sales to the grid. The OC strategy makes use of the cheaper PV and stored battery energy whenever available to power the HPWH and load. The grid's direct supply to the HPWH is restricted by the binary variable $u_{1}(k)$ switch, ( 1 or 0 , when On/Off respectively) and can only be $O n$ if the PV and the battery power is uneconomical to use dependent on the TOU/feed-in tariff or is completely unavailable. The weighting

\footnotetext{
${ }^{1}$ http://www.eskom.co.za/

${ }^{2}$ http://www.nersa.org.za/

${ }^{3}$ https://energypedia.info/wiki
} 
factor $\omega$ is adjusted based on the desired effects (e.g savings on energy or maximum rebate) of the customer. The sampling time $t_{s}$ in this model is one hour and the sampling interval $k=1, \ldots, N$ where $N=24$.

Objective function:

$$
J=t_{s}\left(\omega_{1} p(t) \sum_{k=1}^{N}\left(P_{1}(k)+P_{2}(k)+P_{5}(k)\right)-\omega_{2} p_{c} \sum_{k=1}^{N} P_{8}(k)\right),
$$

subject to the following constraints:

$$
\begin{gathered}
P_{1}(k) u_{1}(k)+P_{3}(k)+P_{7}(k)=P_{h p}(k), \\
0 \leq P_{6}(k)+P_{7}(k)+P_{8}(k) \leq \eta_{i} P_{p v}(k), \\
B_{c}(k)=B_{c}(0)+\eta_{i} \eta_{c} \sum_{\tau=1}^{k} P_{2}(\tau)-\eta_{i} \eta_{d} \sum_{\tau=1}^{k} P_{3}(\tau)-\eta_{i} \eta_{d} \sum_{\tau=1}^{k} P_{4}(\tau), \\
P_{4}(k)+P_{5}(k)+P_{6}(k)=P_{d l}(k),
\end{gathered}
$$

where $p(t)$ and $p_{c}$ is the TOU electricity tariff and the PV feed-in tariff $(R / k W h)$.

\section{Control variables and limits}

The model is a mixed integer nonlinear problem with continuous and binary control variables. The continuous variables are the power flows $P_{1}(k), P_{2}(k), P_{3}(k), P_{4}(k), P_{6}(k), P_{7}(k)$ and $P_{8}(k)$ while the switch $u_{1}(k)$ is a binary variable which can only assume values ( 0 or 1$)$. The upper and lower bounds of the continuous variables are given in equation (15) for every $k^{\text {th }}$ sampling interval. The continuous variables are $P_{i}(k)$, where $i=1,2, \ldots, 8$.

$$
P_{(i)}^{\min } \leq P_{i}(k) \leq P_{(i)}^{\max }
$$

\subsection{Mixed Integer Nonlinear Programming (MINLP)}

The objective function contains a linear and nonlinear constraints with a binary variable. The power supply to the HPWH is control by the switch $u_{1}(k)$ and a continuous variable $P_{1}(k)$. This makes the problem to be a mixed integer nonlinear, which is formulated according to [34]. An additional MINLP optimization solver OPTI toolbox in MATLAB was used.

The general OPTI toolbox algorithm solver is formulated as follows: 


$$
\min _{x} f^{T} x \text { subject to }\left\{\begin{array}{l}
A \cdot x \leq b \\
\text { Aeq } \cdot x=b e q \\
l b \leq x \leq u b \\
c(x) \leq d \\
c_{e q}(x)=d_{e q} \\
c(x) \leq d \\
x_{i} \in z \\
x_{j} \in\{0,1\}
\end{array}\right.
$$

$f^{T_{x}}$ is scalar function to be minimised containing the nonlinear objective function, which is subject to the following constraints:

\section{Linear equalities:}

Aeq is a $k \times n$ sparse matrix, beq is a $k \times 1$ vector.

\section{Linear inequalities:}

$A$ is a $m \times n$ sparse matrix, $b$ is a $m \times 1$ vector.

\section{Decision variable bounds:}

$l b$ and $u b$ are $n \times 1$ indicating the lower and upper bound respectively.

\section{Nonlinear inequalities:}

$c$ is a $u \times 1$ vector of functions containing inequality constraints, $d$ is a $u \times 1$ vector.

\section{Nonlinear equalities:}

$c e q$ is a $v \times 1$ vector of functions containing nonlinear equality constraints, deq is a $v \mathrm{x} 1$ vector. Integer constraints:

$x_{i}$ are decision variables which must be an integer number $z$.

Binary constraints:

$x_{j}$ are decision variables which must be a binary number $(0,1)$, where $i \neq j$.

\subsection{Case study}

A case study is done based on 3x16 kW HPWH installed at a Pretoria Hotel in South Africa. The power consumption of the HPWH was measured at hourly intervals for a year. The power consumed by the heat pump is directly proportional to the thermal energy flow requirement and 
inversely proportional to its system COP. The simplified hourly power demand of the HPWH is given as:

$$
P=\frac{Q_{D}}{C O P}
$$

where $Q_{D}$ is the total thermal demand which is a function dependent on mass and energy balance of the system. In Figure 2 shows the hourly energy consumption of the HPWH on a selected date of the month considered in the case study. The energy consumed by the other domestic load in exception of the HPWH were also measured and treated as input data. The months in the case study were selected from each prevailing season in South Africa. The baseline is the current situation at the hotel where the HPWH and domestic load is supplied by the grid only. The rooms in the hotel are fitting with occupancy sensing system, a lower level energy management. The proposed OC strategy is main intervention which considers the TOU tariff. This model yielded a significant energy and cost reduction presented in section 3.

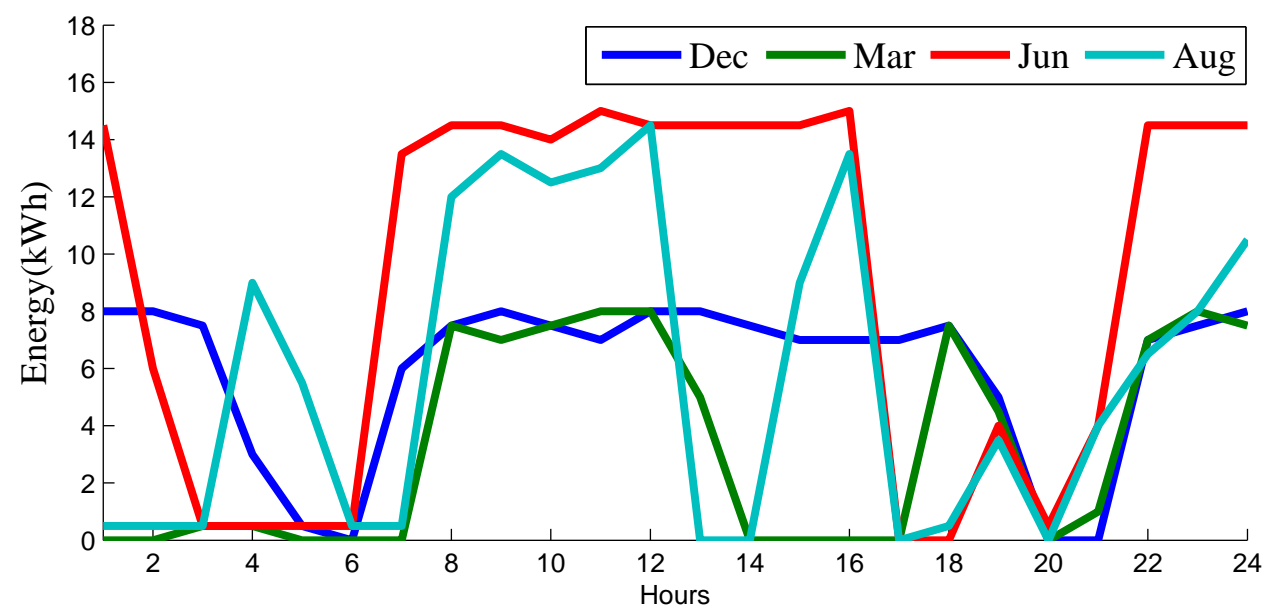

Figure 2: HPWH hourly energy consumption $(k W h)$

The input data on the PV power generation shown Figure 3 is adopted from the measured data from our on going research [35] on a tilted roof-top mounted PV modules. The PV arrays are mounted on a $66.2 \mathrm{~m}^{2}$ roof-top area. The month of December is observed with an erratic PV power generation because of being summer period in South Africa, characterised by heavy cloud and rain. 


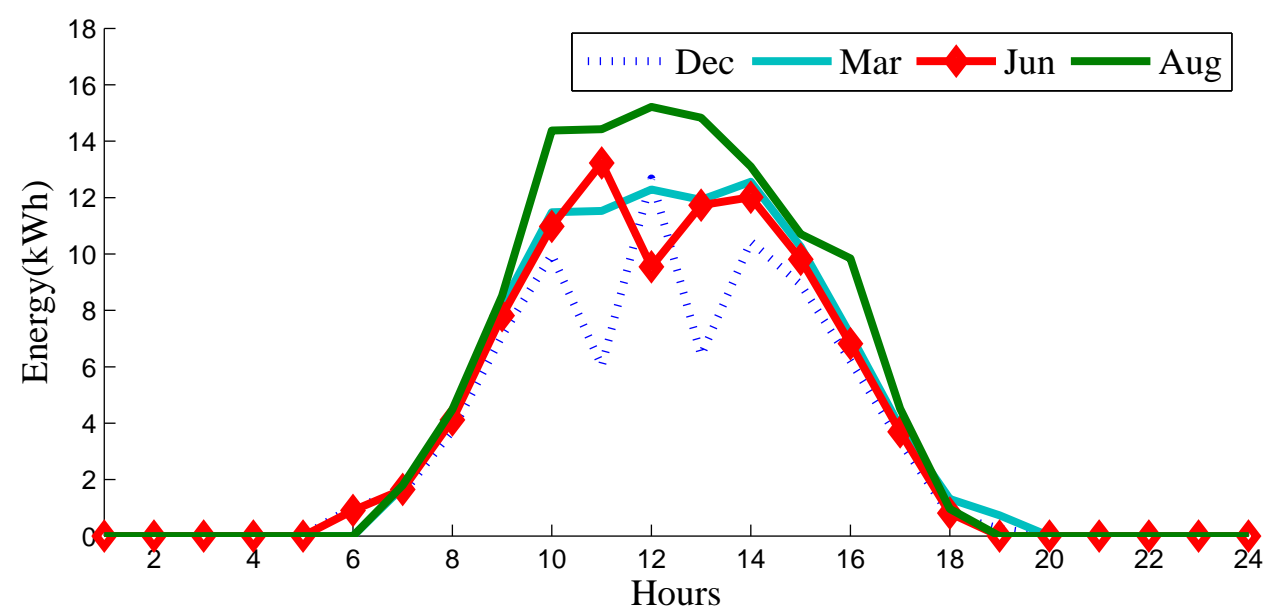

Figure 3: PV power output $(k W)$

The deep cycle battery SunXtender ${ }^{4}$ type-PVX-2580L is used, with the total capacity of 3x165A-h. The battery capacity is deliberately undersized to reduce on the initial investment cost and to hold only enough power to supplement the grid during peak demand. During off-peak period the grid charges the battery, this power is released during peak TOU tariff to the HPWH and the domestic loads. It is assumed that the initial SOE of the battery is $B_{c}(0)=0.55 B_{c}^{\max }$.

\section{Simulation results and discussion}

\subsection{Optimal control strategy of the heat pump water heater and domestic load-December}

The optimal schedule in December Figure 4(a) shows the power from the grid $\left(P_{1}\right)$ and battery $\left(P_{3}\right)$ meeting the HPWH demand $\left(P_{h p}\right)$ from midnight till 06:00 in the morning. The OC prioritised the battery to power the HPWH up to the starting of standard TOU tariff. The grid supply around 04:00 shuts down as shown in Figure 4(b), instead the stored energy is used to supply the HPWH. However, in Figure 4(b) the OC switches On again the grid supply to the HPWH at 05:00 and kept it on standby, though no power is flowing. This could be attributed to fact that the OC opted to use the cheaper stored energy, but still kept the grid on standby in case of the battery fails to sustain the HPWH. The schedule changed when the tariff entered peak TOU, it shows that the PV $\left(P_{7}\right)$ and the battery $\left(P_{3}\right)$ supplying much of the HPWH demand, thereby avoiding the expensive energy from the grid. The battery continued supplying the required demand after peak period, and the grid just supplemented. The PV dropped supply immediately after peak demand, the generated 
power $\left(P_{8}\right)$ is sold Figure 5(a) to the grid in order to maximise the benefits. The SOE in Figure 5(b) was increasing after peak period, meaning the battery is storing more energy than what is being discharged to the loads. The OC switching frequency is low in peak period Figure 4(b) in order to save energy from the grid. The OC followed the similar schedule in the evenings. The TOU electricity tariff legend in Figure 4 applies to all results in this paper.
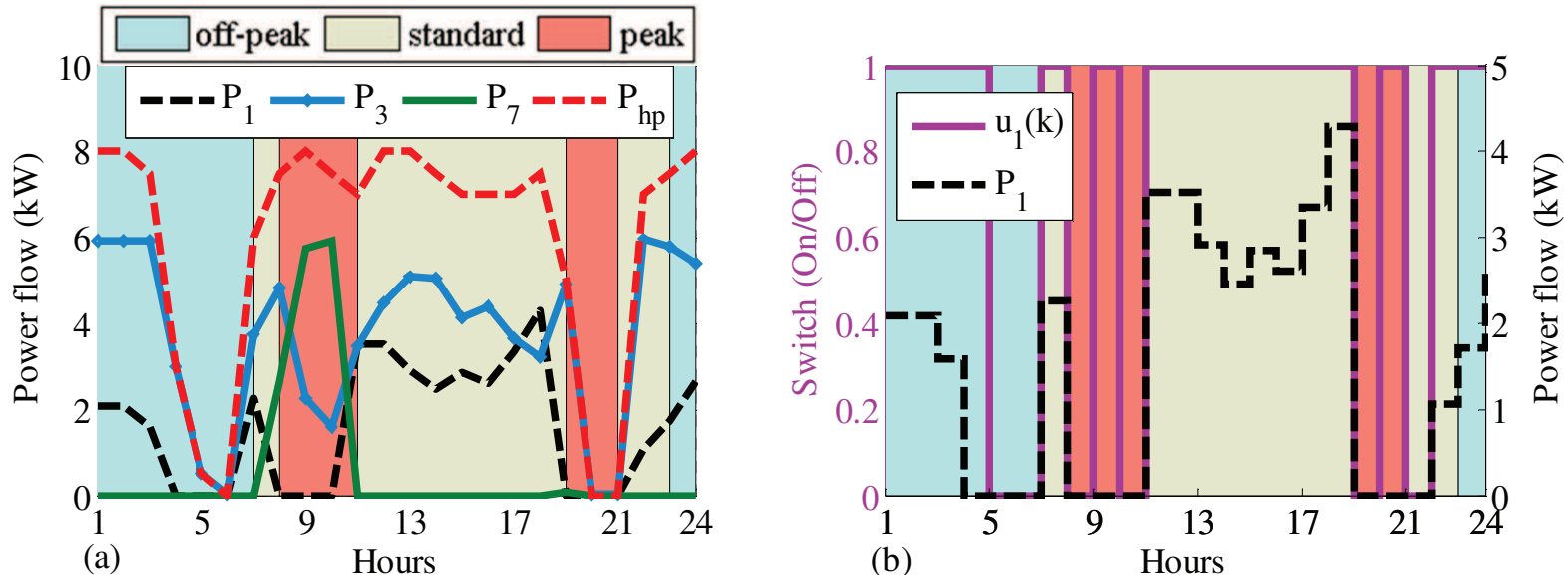

Figure 4: (a) Optimal power dispatch to the HPWH; (b) Optimal switching control to the HPWH

The power dispatched to the domestic load is presented in Figure 5(a). The battery $\left(P_{4}\right)$ supplied the entire load from midnight until 07:00 before the grid $\left(P_{5}\right)$ is brought into supply. The PV $\left(P_{6}\right)$ supplied the domestic load only during peak demand, afterwards all the generated power is traded-off to the grid.

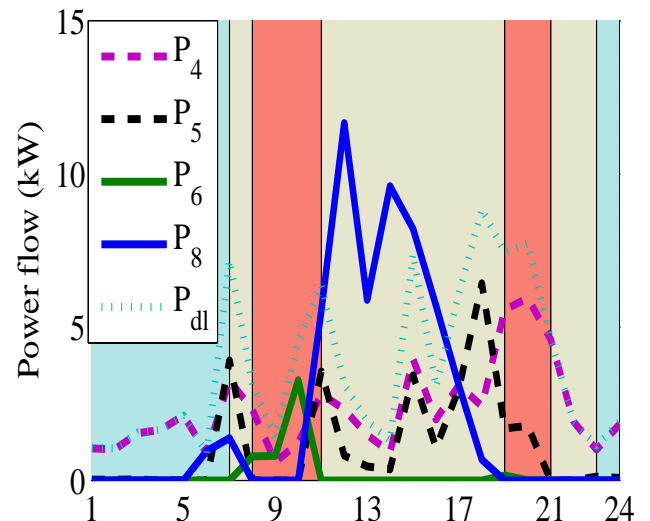

(a)

Hours

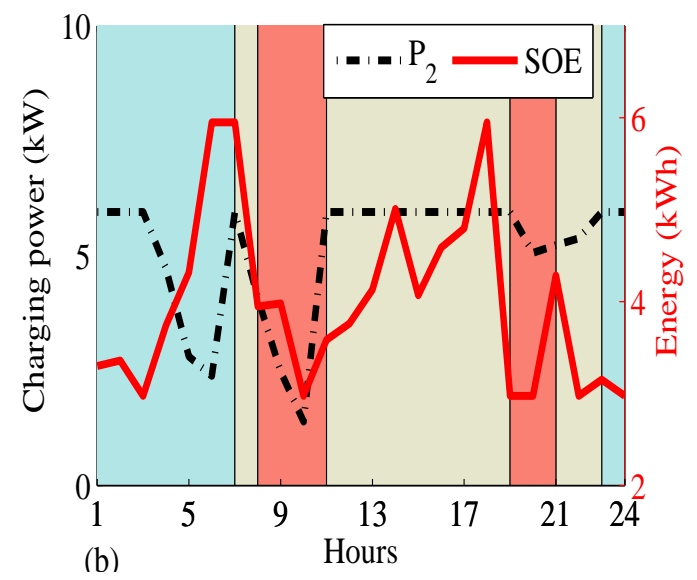

Figure 5: (a) Optimal load scheduling and solar sales; (b) Status of charge and battery power dispatch

While Figure 5(b) shows the battery status of energy $(S O E)$ and the dispatched power to the HPWH $\left(P_{3}\right)$ and domestic load $\left(P_{4}\right)$. The battery is only charged through $\left(P_{2}\right)$ during the off-peak 
and standard TOU tariff. The SOE rose during these periods, meaning the battery is accumulating cheaper energy that will be made available during peak demand. During peak TOU the SOE declined because the battery was discharging the stored power to the loads. The schedule is observed to drop the grid power supply $\left(P_{2}\right)$ to the battery during peak period to save on energy cost.

\subsection{Optimal control strategy of the heat pump water heater and domestic load-March}

In March Figure 6(a) the power consumed by the HPWH is relatively less when compared to the month of December. The PV power $\left(P_{7}\right)$ supplied much of the morning peak, with supplement from the battery $\left(P_{3}\right)$. The grid supply $\left(P_{1}\right)$ to the HPWH is off the whole period and came in at the beginning standard TOU period. The PV supply gradually dropped and the cheaper battery energy sustained the supply to the HPWH till 14:00. The optimal schedule in the evening followed similar trend,the battery is charging in this period as shown by the SOE in Figure 7(b). The stored energy, thereafter, supplied most of the HPWH demand throughout to midnight. The OC in Figure 6(b) shows a low switching frequency matching the low load demand. The grid supplied power only during standard TOU tariff, which is beneficial on cost saving.
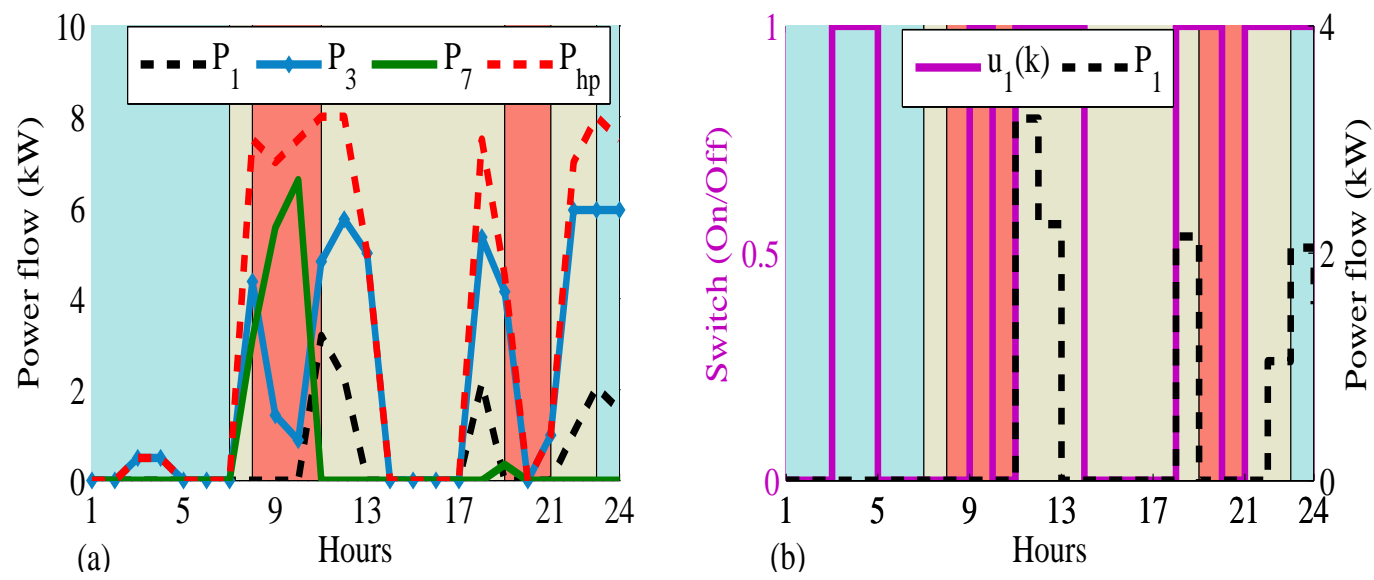

Figure 6: (a) Optimal power dispatch to the HPWH; (b) Optimal switching control to the HPWH

The load demand shown in Figure $7(a)$, is met by the battery $\left(P_{4}\right)$ throughout the day except during peak period. The PV supplied much of the peak period, thereafter the battery continued. This change of the OC strategy was not as result of the TOU, but rather to satisfy the load demand using economical energy. However, most of the morning peak demand is met by the PV power. The excess solar power $\left(P_{8}\right)$ is sold to the grid. The grid $\left(P_{5}\right)$ barely supplied the domestic load because the OC always prioritised the stored cheaper energy. 

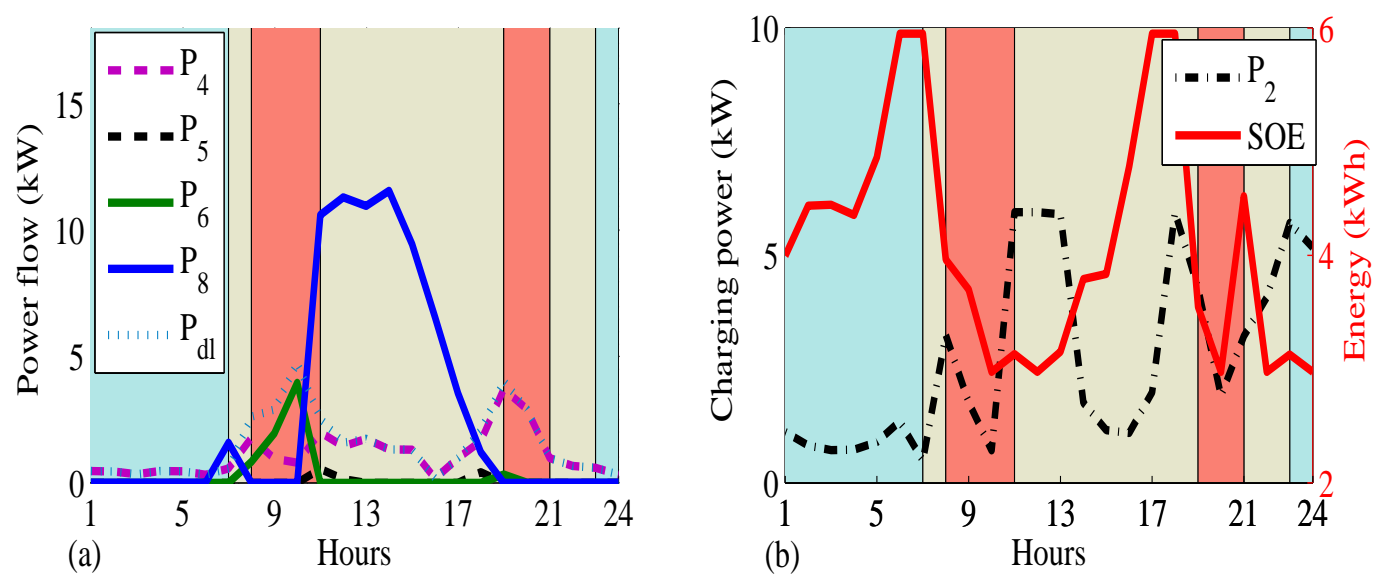

Figure 7: (a) Optimal load scheduling and solar sales; (b) Status of charge and battery power dispatch

The SOE in Figure 7(b) showed the battery is storing energy from midnight till the beginning of morning standard TOU tariff. The battery, however, discharged most of the energy during peak demand, subsequently the SOE in Figure 7(b) declined between 07:00 and 11:00. Though as the tariff entered standard TOU again the charging resumed.

\subsection{Optimal control strategy of the heat pump water heater and domestic load - June}

The month of June Figure 8(a) has the highest power demand. The HPWH demand was high throughout the day because it is a winter period of the year in this case study, characterised by higher thermal requirement for bathing and space heating. The grid $\left(P_{1}\right)$ supplied the HPWH from midnight till morning with minor supplement from the battery $\left(P_{3}\right)$. The switching frequency in Figure 8(b) was different from the rest of the year. The OC switch is $O n$ throughout morning peak TOU despite having the complimentary sources. This can also be attributed to the low PV power output as shown in Figure 3 in winter, solar irrandiance is low in southern hemisphere because of the sun's geometrical position. 

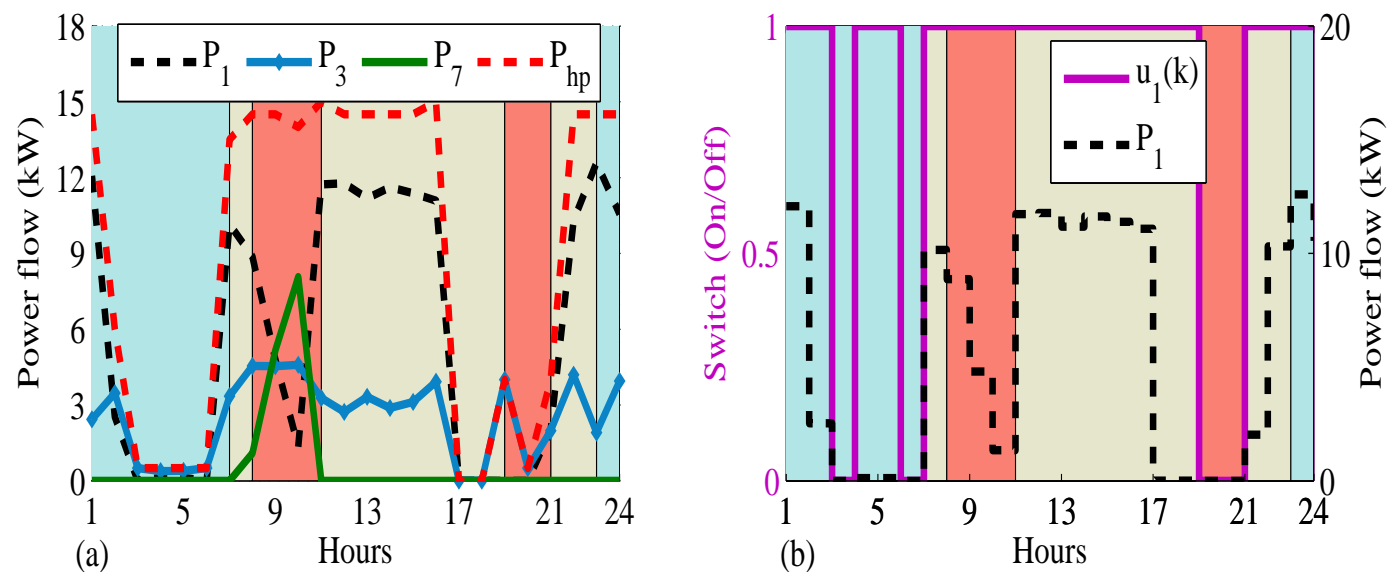

Figure 8: (a) Optimal power dispatch to the HPWH; (b) Optimal switching control to the HPWH

The power scheduling to the load in Figure 9(a), shows the grid $\left(P_{5}\right)$ supplied the most of the domestic demand with the help of the battery. In Figure 9(b), the battery SOE showed a continuous oscillation for the whole period, charging and discharging. The SOE frequent cycles have a negative effect on the battery life. The grid power $\left(P_{2}\right)$ charging the battery is steady throughout owing to the increased discharge frequency of the battery.
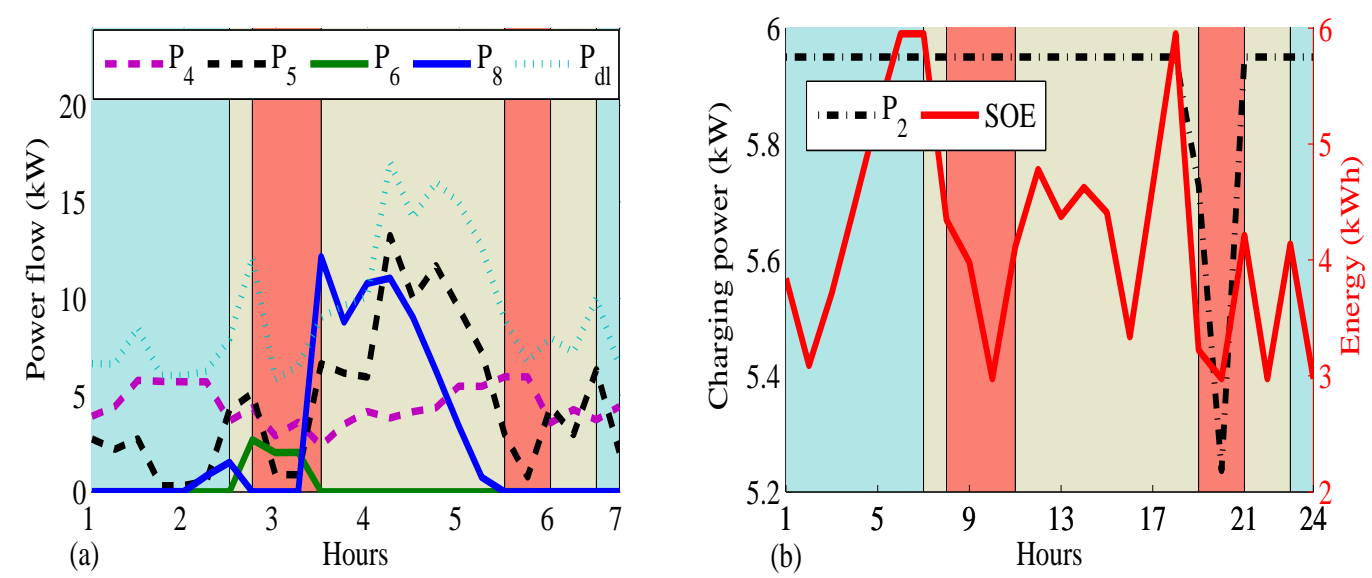

Figure 9: (a) Optimal load scheduling and solar sales; (b) Status of charge and battery power dispatch

Despite having the highest demand, solar energy sales are relatively better than in December as shown in Table 1 due to the absence clouds and rain. Though, June had the lowest cost savings.

\subsection{Optimal control strategy of the heat pump water heater and domestic load-August}

The optimal scheduling strategy in August Figure 10(a) is similar to that of the previous months discussed above. August had the best solar irradiance which increased the PV power output. In 
additional, there is an increase in the solar power sales $\left(P_{8}\right)$ to the grid as showed in Figure 11(a). The generated revenue are as well more during this month, when compared to other seasonal months.
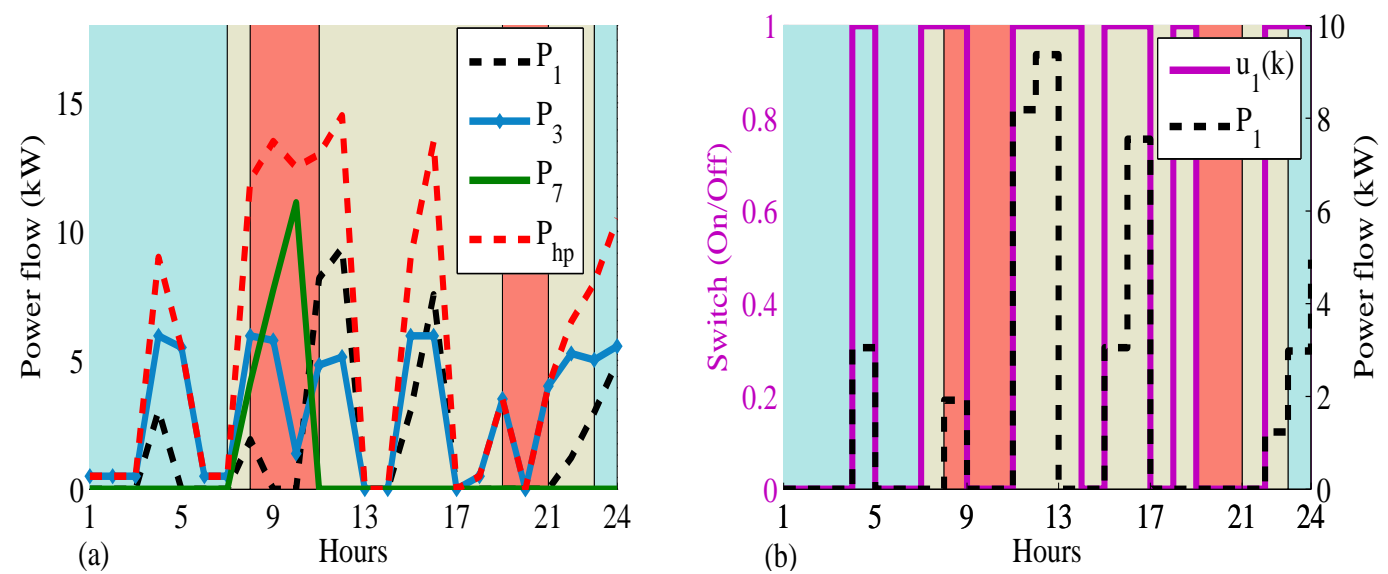

Figure 10: (a) Optimal power dispatch to the HPWH; (b) Optimal switching control to the HPWH

The battery SOE Figure 11(b) showed the battery had enough stored capacity except during the peak demand. The HPWH load was erratic in Figure 10(a) which is depicted by $\left(P_{3}\right)$ however, the OC prioritise usage of the store energy in the battery.
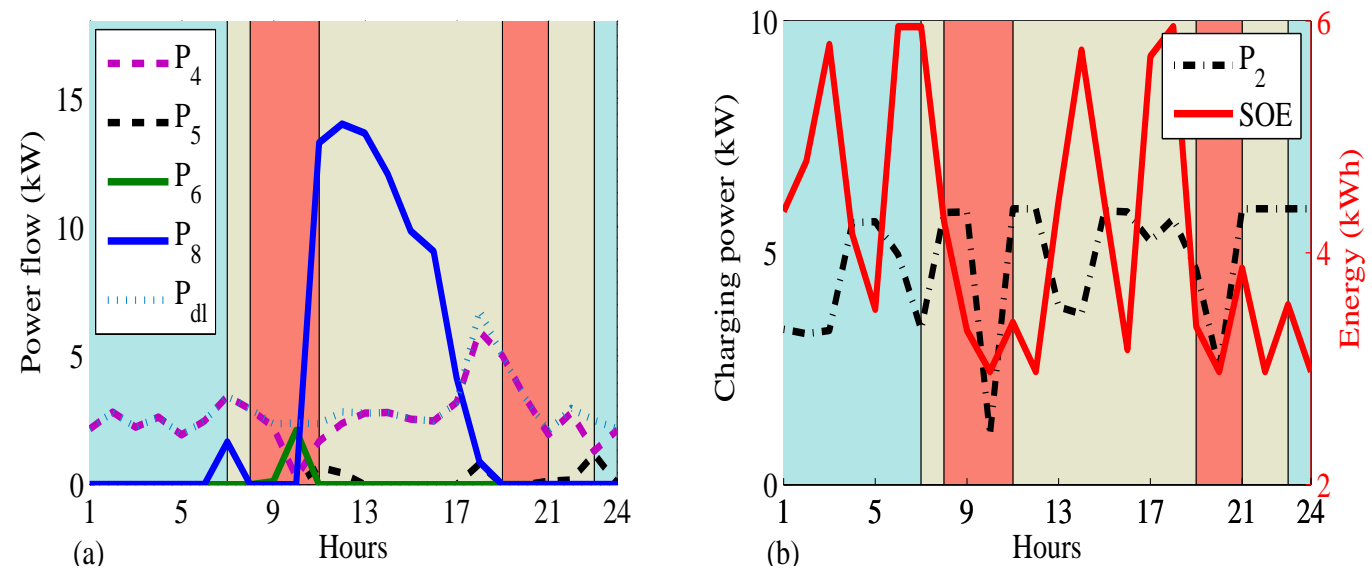

Figure 11: (a) Optimal load scheduling and solar sales; (b) Status of charge and battery power dispatch

The optimal control show huge savings on the grid side owing to the power-not-delivered. The optimal energy mixing, saving and renewable energy feed-in is achieved, presented below in Table 1. The challenges in achieving the NZEBs would be solved by the implementation of this model. 


\subsection{Baseline and optimal energy cost}

The baseline energy cost is the current situation in the case study, where the grid meets all the total demand of the HPWH and loads. The optimal cost, on the other hand, is the energy cost after employing the optimal control strategy presented in this paper. The optimal cost comprises the sum of energy consumed by the domestic load, HPWH and the energy used to charge the battery. The proposed integration of PV energy yield great benefit on cost saving which are presented in Table 1 . The PV energy sales is the revenue generated by selling solar energy to the power grid. Though, not all the produced PV power is sold, some goes to supplement the load demand.

The energy saved represent the power utility (grid) power-not-delivered to the load, which would have been delivered without the OC intervention of this model. The saved energy basically is the difference between the baseline and the OC strategy. There are significant energy saving which directly translated into a reduction on primary input of the utility power generation (e.g., gas, coal and water). The consumption of more primary input in the generation of power comes with negative effect on global warming. However, these impacts are not considered in this paper. The results in Table 1 are the energy and cost saving per day, on the selected dates in the case study.

Table 1: Daily optimal energy and cost savings

\begin{tabular}{cccccc}
\hline Month & Baseline cost (R/day) & Optimal cost (R/day) & Solar sales (R/day) & Energy saved (kWh) & Cost savings (\%) \\
\hline December & 219.03 & 146.27 & 207.70 & 72.11 & 33.22 \\
March & 138.39 & 65.68 & 263.03 & 89.46 & 52.54 \\
June & 400.32 & 319.29 & 254.47 & 85.66 & 20.24 \\
August & 212.06 & 126.92 & 309.53 & 103.75 & 40.15 \\
\hline
\end{tabular}

The optimal scheduling strategy showed a maximum energy cost savings of $52.54 \%$ in March. For example, the month of December had a baseline cost of 219.03R/day and after optimization the cost reduced to $146.27 \mathrm{R} /$ day which translated to a cost saving of $33.22 \%$. The monthly energy cost if it is assumed to be constant daily demand, for December with 31 calender days the costs would be: baseline cost 6789.93R/month, optimal cost 4534.37R/month, PV energy sales 6438.7 R/month and energy saving amounting to $2235.41 \mathrm{kWh} /$ month. The optimal scheduled presented a huge benefit especially that the battery acts as the storage of the cheaper-to-purchase energy from the grid.

The month of June had the lowest energy cost savings which stood at $20.24 \%$ because of higher load demand in winter. On the other hand, August had the highest solar sales at 309.53R/day 
mainly because of the better solar irradiance and clear sky in southern hemisphere. The huge revenue from the PV energy sales in part is attributed to the attractive feed-in tariff in this case study. The hotel is energy cost-positive in some of the days, though not on energy. The main intervention of optimal schedule achieved energy and cost savings.

\subsection{Economic analysis}

The economical analysis is done with the following assumptions: A discount factor or interest rate of $5.9 \%$ is used to reflect the time value of money and the $5.9 \%$ is indicative of the inflation rate in South Africa. Thus the discounted present value (DPV $)^{5}$ for one cash flow in one future period is expressed as:

$$
D P V=\frac{F V}{(1+r)^{n}}
$$

where

$D P V$ - is the discounted present value of the future cash flow (FV); $F V$ - is the nominal value of a cash flow amount in a future period;

$r$ - is the interest rate or discount rate, which reflects the cost of tying up capital and may also allow for the risk that the payment may not be received in full; $n$ - is the time in years before the future cash flow occurs.

The Table 2 below show the revenue from solar energy sales and the benefit on cost savings owing to the OC intervention, based on the average of all the months tested in the case study, and then the costs/revenue of that day is annualized to reflect an average amount per annum.

Table 2: Annualised benefits

\begin{tabular}{lrrrr}
\hline & Baseline costs & Optimal & Solar sales & Savings \\
\hline & 219.03 & 146.27 & 207.7 & \\
& 138.39 & 65.68 & 263.03 & \\
& 400.32 & 319.29 & 254.47 & \\
\hline Average & 212.06 & 126.92 & 309.53 & \\
\hline Annualised benefits & 242.45 & 164.54 & 258.6825 & 77.91 \\
\hline
\end{tabular}

It's assumed that the solar sales, cost savings, operations and maintenance costs will remain constant throughout the period. Though it is expected that there would be an increase in all these

\footnotetext{
${ }^{5}$ https://en.wikipedia.org/wiki/Discounted-cash-flow
} 
factors, it cannot be reliably estimated at this time. Increases in solar sales and costs would reduce the payback period. The detailed economical analysis of payback period is shown in the Table 3 .

Table 3: Payback period

\begin{tabular}{|c|c|c|c|c|c|c|}
\hline Years & 0 & 1 & 2 & 3 & 4 & 5 \\
\hline Solar modules & $(160000.00)$ & & & & & \\
\hline Deep cycle battery & $(28760.00)$ & & & & & \\
\hline Energy manager controller & (75 900.00) & & & & & \\
\hline Inverter/charger for the battery & (26 490.00) & & & & & \\
\hline PV grid-interactive inverter & (42 188.00) & & & & & \\
\hline ZigBee load control switches & (15 227.00) & & & & & \\
\hline Installation cost & $(25000.00)$ & & & & & \\
\hline Operation and maintenance cost & & $(33725.00)$ & $(33725.00)$ & $(33725.00)$ & $(33725.00)$ & $(33725.00)$ \\
\hline Solar sales & & 94419.11 & 94419.11 & 94419.11 & 94419.11 & 94419.11 \\
\hline Cost Savings & & 28437.15 & 28437.15 & 28437.15 & 28437.15 & 28437.15 \\
\hline & (373 565.00) & 89131.26 & 89131.26 & 89131.26 & 89131.26 & 89131.26 \\
\hline Discount factor @ 5.9\% & 1 & 0.944287063 & 0.891678058 & 0.842000055 & 0.795089759 & 0.750792973 \\
\hline Discounted cashflows & (373 565.00) & 84165.50 & 79476.39 & 75048.53 & 70867.35 & 66919.13 \\
\hline \multirow[t]{7}{*}{ Discounted Payback Period } & Years & cashflows & ashflows & & & \\
\hline & $\overline{0}$ & $(373565.00)$ & $(373565.00)$ & & & \\
\hline & 1 & 84165.50 & (289 399.50) & & & \\
\hline & 2 & 79476.39 & (209 923.11) & & & \\
\hline & 3 & 75048.53 & (134 874.58) & & & \\
\hline & 4 & 70867.35 & (64 007.23) & & & \\
\hline & 5 & 66919.13 & 2911.90 & & & \\
\hline
\end{tabular}

Table 3 clearly shows that the discounted payback period goes up to fourth year, when the invested capital indicated in brackets in Table 3 reaches the break even point. By exactly 4 years and 11 months this proposed system would have completely paid back the capital investment. Though, as mentioned above assumptions were made to certain factors that may influence the payback period, that is the cash flows and maintenance costs are treated to be constant. These factor, though, have minimal effects on this proposed model making it economically feasible with a shorter payback period.

\section{Conclusions}

The optimal scheduling strategy presented in this paper shows huge energy cost savings. The analysis reviewed novel optimal scheduling with respect to the TOU electricity tariff to power the HPWH. The HPWH's operational constraints were satisfied through the use of the actual performance index in this paper. The scheduling strategy presented a practical integration of renewable resources to the grid in order to achieve NZEBs. The current rebate system on the usage of HPWH for generation of hot water in place of the resistive element heaters (geysers) in South Africa will further increase the market penetration. The application of this model would farther reduce initial investment costs. In respect to global call for climate change awareness most building owners are 
now looking for energy-efficient and sustainable technologies. Though this model presents such solutions, the future research should look into integration of other renewable energy sources (e.g biomass, wind) to specifically supply the HPWH.

The initial investment payback would be further reduced with rebate on the usage of HPWHs and DREs in South Africa, which were not considered in this paper. The case study showed that for some of the period the building is energy cost-positive, meaning the utility bills could be paid from the generated revenue. The model result showed huge revenue from solar energy sales, in addition Eskom gives rebate on HPWH which is not considered in this paper. The grid-connected PV optimal scheduling strategy could be applied to realise sustainable energy integration for low demand loads such as HPWHs. This would improve utility's power reserves and security of supply through optimal integration of DRE sources. In addition, employing of the battery as an offpeak energy storage system had a positive benefit as the building could qualified for rebates and incentives on renewable energy trade-off.

This model is suitable for application in both urban and rural areas. There are several advantages of this model, in that, it is also suitable in the region with intermittent electrical power supplies. The model as well overcame the solar thermal heater's limitations, because it can generate both thermal and electrical energy economically, with a potential to realize an energy-positive and NZEBs.

\section{References}

[1] K. Chua, S. Chou, W. Yang, Advances in heat pump systems: A review, Applied Energy 87 (12) (2010) 3611-3624.

[2] C. Verhelst, F. Logist, J. Van Impe, L. Helsen, Study of the optimal control problem formulation for modulating air-to-water heat pumps connected to a residential floor heating system, Energy and Buildings 45 (2012) 43-53.

[3] N. Pardo, Á. Montero, J. Martos, J. Urchueguía, Optimization of hybrid-ground coupled and air source-heat pump systems in combination with thermal storage, Applied Thermal Engineering 30 (8) (2010) 1073-1077.

[4] P. Rousseau, G. Greyvenstein, Enhancing the impact of heat pump water heaters in the south african commercial sector, Energy 25 (1) (2000) 51-70. 
[5] M. Hawlader, S. Chou, M. Ullah, The performance of a solar assisted heat pump water heating system, Applied Thermal Engineering 21 (10) (2001) 1049-1065.

[6] M. W. Ahmad, M. Eftekhari, T. Steffen, A. M. Danjuma, Investigating the performance of a combined solar system with heat pump for houses, Energy and Buildings 63 (2013) $138-146$.

[7] T. Chow, Y. Bai, K. Fong, Z. Lin, Analysis of a solar assisted heat pump system for indoor swimming pool water and space heating, Applied Energy 100 (2012) 309-317.

[8] E. Kjellsson, G. Hellström, B. Perers, Optimization of systems with the combination of ground-source heat pump and solar collectors in dwellings, Energy 35 (6) (2010) 26672673.

[9] J. Ji, G. Pei, T.-t. Chow, W. He, A. Zhang, J. Dong, H. Yi, Performance of multi-functional domestic heat-pump system, Applied Energy 80 (3) (2005) 307-326.

[10] J. Zhang, R. Wang, J. Wu, System optimization and experimental research on air source heat pump water heater, Applied thermal engineering 27 (5) (2007) 1029-1035.

[11] H. Yin, D. Yang, G. Kelly, J. Garant, Design and performance of a novel building integrated pv/thermal system for energy efficiency of buildings, Solar Energy 87 (2013) 184-195.

[12] G. Xu, S. Deng, X. Zhang, L. Yang, Y. Zhang, Simulation of a photovoltaic/thermal heat pump system having a modified collector/evaporator, Solar Energy 83 (11) (2009) 19671976.

[13] X. Zhang, X. Zhao, J. Xu, X. Yu, Characterization of a solar photovoltaic/loop-heat-pipe heat pump water heating system, Applied Energy 102 (2013) 1229-1245.

[14] H. Fu, G. Pei, J. Ji, H. Long, T. Zhang, T. Chow, Experimental study of a photovoltaic solarassisted heat-pump/heat-pipe system, Applied Thermal Engineering 40 (2012) 343-350.

[15] G. Mihalakakou, M. Santamouris, D. Asimakopoulos, Modelling the thermal performance of earth-to-air heat exchangers, Solar energy 53 (3) (1994) 301-305.

[16] D. Kolokotsa, D. Rovas, E. Kosmatopoulos, K. Kalaitzakis, A roadmap towards intelligent net zero- and positive-energy buildings, Solar Energy 85 (12) (2011) 3067 - 3084. 
[17] J. O. Luis PeÂŽrez-Lombard, C. Pout, A review on buildings energy consumption information, Energy and Buildings 40 (3) (2008) $394-398$.

[18] A. J. Marszal, J. S. Bourrelle, E. Musall, P. Heiselberg, A. Gustavsen, K. Voss, Net zero energy buildings-calculation methodologies versus national building codes, the Proceedings of EuroSun.

[19] P. Hernandez, P. Kenny, From net energy to zero energy buildings: Defining life cycle zero energy buildings (lc-zeb), Energy and Buildings 42 (6) (2010) 815 - 821.

[20] A. Robert, M. Kummert, Designing net-zero energy buildings for the future climate, not for the past, Building and Environment 55 (0) (2012) 150 - 158.

[21] W. Zeiler, G. Boxem, Net-zero energy building schools, Renewable Energy 49 (0) (2013) $282-286$.

[22] T. Ikegami, Y. Iwafune, K. Ogimoto, Optimum operation scheduling model of domestic electric appliances for balancing power supply and demand, in: IEEE International Conference on Power System Technology, 2010.

[23] H. Tazvinga, X. Xia, J. Zhang, Minimum cost solution of photovoltaic-diesel-battery hybrid power systems for remote consumers, Solar Energy 96 (2013) 292-299.

[24] S. Ashok, Optimised model for community-based hybrid energy system, Renewable energy 32 (7) (2007) 1155-1164.

[25] M. Ismail, M. Moghavvemi, T. Mahlia, Design of an optimized photovoltaic and microturbine hybrid power system for a remote small community: Case study of palestine, Energy Conversion and Management 75 (2013) 271-281.

[26] T. Khatib, A. Mohamed, K. Sopian, Optimization of a pv/wind micro-grid for rural housing electrification using a hybrid iterative/genetic algorithm: case study of kuala terengganu, malaysia, Energy and Buildings 47 (2012) 321-331.

[27] M. Castañeda, A. Cano, F. Jurado, H. Sánchez, L. M. Fernández, Sizing optimization, dynamic modeling and energy management strategies of a stand-alone pv/hydrogen/batterybased hybrid system, International Journal of Hydrogen Energy 38 (10) (2013) 3830-3845. 
[28] A. El-Sebaii, F. Al-Hazmi, A. Al-Ghamdi, S. J. Yaghmour, Global, direct and diffuse solar radiation on horizontal and tilted surfaces in jeddah, saudi arabia, Applied Energy 87 (2) (2010) 568-576.

[29] K. Ishaque, Z. Salam, An improved modeling method to determine the model parameters of photovoltaic (pv) modules using differential evolution (de), Solar Energy 85 (9) (2011) 2349-2359.

[30] M. Ismail, M. Moghavvemi, T. Mahlia, Characterization of pv panel and global optimization of its model parameters using genetic algorithm, Energy Conversion and Management 73 (2013) 10-25.

[31] P. A. Torcellini, D. B. Crawley, Understanding zero-energy buildings, ASHRAE journal 48 (9) (2006) 62-69.

[32] S. Kilkis, A new metric for net-zero carbon buildings, in: ASME 2007 Energy Sustainability Conference, American Society of Mechanical Engineers, 2007, pp. 219-224.

[33] T. Ikegami, K. Kataoka, Y. Iwafune, K. Ogimoto, Optimal demand controls for a heat pump water heater under different objective functions, in: IEEE International Conference on Power System Technology, POWERCON 2012, 2012.

[34] P. Belotti, C. Kirches, S. Leyffer, J. Linderoth, J. Luedtke, A. Mahajan, Mixed-integer nonlinear optimization, Acta Numerica 22 (2013) 1-131.

[35] H. Tazvinga, B. Zhu, X. Xia, Energy dispatch strategy for a photovoltaic-wind-dieselbattery hybrid power system, Solar Energy 108 (2014) 412-420. 